\title{
Leadership and creativity in East Asian schools
}

\author{
Roger C. Shouse ${ }^{1,2} \cdot$ Chenwei Ma $^{1}$
}

Received: 19 September 2014/Revised: 8 October 2015 / Accepted: 27 October 2015/Published online: 2 November 2015

(C) Education Research Institute, Seoul National University, Seoul, Korea 2015

\begin{abstract}
Over the past two decades, the concepts of educational creativity and leadership have attracted tremendous attention throughout East Asia. Driven in large part by isomorphic tendencies within a global organizational environment, the two ideas have also acquired the trappings of institutional myth. Often overlooked in the schools literature, however, are the strong conceptual similarity and interconnection between creativity and leadership. Of particular note in East Asian schools is the intrinsic tension they share between being understood as properties of formal or ascribed status and as natural human characteristics. Based on the prior literature, examples, and analysis, this conceptual paper: (1) examines the "twin concept" nature of creativity and leadership within schools, proposing that they be understood less in terms of formal or ascribed status and more as vectors of natural activity within school organizations; (2) suggests ways in which East Asian school reform movements can take advantage of such activity; and (3) raises questions regarding the meaning of "reform" in East Asian schools.
\end{abstract}

Keywords Leadership - Creativity $\cdot$ School reform $\cdot$ East Asian schooling

Roger C. Shouse

rcs8@psu.edu

Chenwei Ma

cxm782@gmail.com

1 School of Public Administration, Sichuan University, Chengdu, Sichuan, China

2 Present Address: The Pennsylvania State University, 302 Rackley Bld., University Park, PA 16802, USA

\section{Introduction}

In recent years, generated by educational reform trends, East Asian educators have grown interested in the concepts of educational creativity and leadership (Zhao 2007; Shouse 2012). As national systems (China, South Korea, and Taiwan in particular) seek to implement more diverse and creative forms of curriculum and instruction, school "leadership" gains attention as an important tool for achieving this goal (Shouse and Lin 2010). This essay examines the conceptual links between creativity and leadership in educational settings and the peculiar problems they pose for authoritative, hierarchical educational institutions such as those typically found throughout East Asia. In addition, our essay explores the conceptual similarities between creativity and leadership when viewed as natural human phenomena rather than primarily as organizational or bureaucratic traits. Within this naturalistic context, we develop a vector model for understanding creative-leading as a force across fields of policy as well as other fields of human activity.

The tensions posed by demands for creativity and leadership in schools are acute and well illustrated across the various reform movements emerging throughout the East Asian region over the past two decades. In short, schools have been directed to move away from curricular and instructional practices stressing lecture and rote memorization and to devise more interactive practices that encourage creative and collaborative student-centered activity (Sargent 2011; Lockette 2012). They are asked to make this shift, however, under conditions in which teacher (and administrator) freedom to lead or innovate is highly restricted by high stakes testing structures (Dello-Iacovo 2009; Shouse and Lin 2010). This problem is further exacerbated by widely held East Asian cultural norms 
reinforcing the belief that (1) leadership is a function of rank involving the control of subordinates within a framework within which dissent is discouraged (Lockette 2012) and (2) creativity is an attribute reserved for those who have earned the right to exercise it through acquired expertise (Shouse 2012). The combination of organizational and social structure described here leads to conditions under which creativity and leadership will either essentially not develop or will become interpreted in "counterproductive" fashion (Illich 1973), that is, in ways that reinforce institutionalized routines, thereby reducing the likelihood of critical innovation.

The purpose of the present study is thus to trouble current institutionalized understandings of leadership and creativity - to critique these current views and offer new configurations for their meaning in the context of educational reform. Drawing from authentic and hypothetical examples, primarily from China (including Taiwan) and the USA, we suggest that while creativity and leadership are constrained by traditional structures, they can nevertheless be nurtured even in hierarchical organizations - that even rigid systems are capable of establishing a "sweet spot" in which educational innovation can evolve.

\section{Problematic meanings}

\section{Leadership}

Leadership has been described as a "slippery phenomenon elusive to both common sense and social science" (Selznick 1957; Shouse and Lin 2010, 17). Despite a multitude of studies over the years since this description, leadership remains an elusive and often contested concept. In essence, leadership represents the changing of minds and the mobilization of collective volition. Leadership is the process by which individuals and communities gradually and voluntarily come to accept ideas or products they had previously believed were unnecessary, unwise, or irrelevant. It is this volitional aspect that distinguishes leadership from related concepts like management, authority, or power (Haller and Strike 1986). Conceptual slipperiness arises, however, as leadership comes to be understood or defined in terms beyond phenomenon or process, as formal position, rhetorical device, or institutional mechanism aimed at achieving specific results.

In much of East Asia, for example, "leading" is associated with formal rank or position (Begley 2002). The principal is presumed to lead a school, even when engaged primarily in managerial activity. Though this idea of leader as "person in charge" is also common in Western thought and literature, a distinctive and long-standing view also recognizes expressions of leadership by individuals without formal rank or authority. The idea of "informal" leadership, though often viewed as crucial for the attainment of organizational goals and overall school improvement (Hoy and Miskel 1996), meets with resistance in some East Asian settings. For example, Shouse and Lin (2010) reported how Taiwan school principals believed that teachers could show leadership only in their classrooms or by "moving up the ranks." At the same time, these principals also revealed a deep reliance on their teachers" ability to "show the way" toward successful school reform. In other words, while they hoped their teachers would help move the school toward innovation, they refrained from describing such action as leadership. A similar tension seems likely to emerge in Chinese mainland schools as they strive to institute "suzhie jiaoyu" ("quality education") (Ma 2014).

The words "leader" or "leadership" become more problematic when used rhetorically, to recognize success, legitimize particular goals, and reward certain forms of behavior. Leithwood and Riehl (2005, 13-14) suggest such rhetoric when describing educational leadership as actions aimed at "mobilizing and influencing others to articulate and achieve the school's shared intentions and goals," and asserting that "educational leadership that purports to serve any end other than student learning is viewed as illegitimate and ineffectual." Such characterizations add trappings of formal authority to the concept of educational leadership, blur its processes and results, and burden it with vagaries such as "student learning" and "shared intentions and goals." This infusion of formal goals and authority into the leadership concept represents a co-optation into a larger and more entrenched socio-organizational mechanism that works to limit or distort its independent, human, and volitional characteristics.

This type of institutional co-optation may not seem unusual or surprising, as leadership is often invoked and applied for purposes of organizational improvement. But leadership is also a natural, grassroots phenomenon rising from the need for human liberation in social and organizational contexts and in both East and West. It thus seems problematic for the concept to become primarily subsumed as a mechanism useful for maintaining established systems or routines. Such institutionalization of the leadership concept fits with Illich's notion of the "second watershed," the point at which a humanistic tool or social movement is constrained from liberative usage, that is in ways that might help deconstruct, reimagine, and reconfigure the established institutions of which it has become part (Illich 1973).

Although "leadership" has also been defined in ways more naturalistic and neutral with respect to formal goals, structures, and rank (Hoy and Miskel 1996; Spillane 2006), one feels empirically safe to note the expanding tacit acceptance of hierarchical authority within practical and scholarly studies emanating from the USA. Over the past 
decade, for instance, the rising influence of nationalized "standards for educational leadership" has prompted university "educational leadership" programs to shift emphasis toward professional training-despite scholarly criticism of their value, their detrimental impact on local and professional autonomy, and their overall "freezing" effect on the field of educational administration (English 2006). Rarely, even in American "teacher leadership" programs does one find instruction aimed at raising educator capability of reflecting upon and, if necessary, challenging policies imposed by higher levels of management or government (Shouse 2013).

Thus, in both East Asian and Western settings, the idea of leadership becomes melded with the interests of institutional stability and in ways that can discourage organizational diversity and innovation. Such institutional commandeering runs at odds with studies suggesting that leadership can arise from and even produce organizational instability born out of general dissatisfaction with existing formal routines or structures. Dissatisfaction is said to help mobilize voluntary consideration and implementation of ideas or practices previously believed to be irrelevant, unnecessary, or even detrimental (Haller and Strike 1986; Shouse and Lin 2010; Ma 2014). Such emergent forms of leadership are said to evolve in settings of "juxtaposition of order and disorder" and have been cited as a necessary condition for organizational learning (Weick and Westley 1996). Emergent leadership is also likely to thrive within communities where there exists a flexible zone of acceptance (Barnard 1938; Haller and Strike 1986)—a sociopsychological space of propensity to suspend judgments regarding unusual ideas and innovations. Released from institutional pilings, an emergent leadership process may restore stability as new routines and structures gradually evolve-at least until the next wave of dissatisfaction.

Two key points follow from this discussion: First, to view educational leadership primarily as a quality or right of formal authority works to restrict the opportunity, willingness, and action of those individuals and groups having a relatively high capacity to innovate within schools, e.g., teachers and students. Second, we suggest that innovation serves as the conceptual link between leadership and creativity. The impact of both processes depends on persuading people to voluntarily accept new ideas, actions, and products as legitimate and valuable. To be clear, however, as shall be discussed later in this essay, the processes of leadership and creativity exist independently of their results and may not always produce successful outcomes.

\section{Creativity}

Creativity is also an elusive concept, understood from widely assorted perspectives. A general distinction is noted between "big c" and "little c" creativity, thought or action that leads to ideas or artifacts that are widely considered novel and valuable, as opposed to thought or action on a less noticeable or more personal scale (Kozbelt et al. 2010). While some theorize creativity as a cognitive or psychological trait (e.g., Csíkszentmihályi 1996), others emphasize the external, environmental conditions that allow creative thought to emerge (e.g., Carson 2011).

In educational settings, we often speak of creative teaching, creative learning, or creative classroom activity generally, but, like the word leadership, we often use it in hindsight to bestow approval upon a series of successful ideas or products. This utilitarian sense is expressed in questions like "how can we teach students to become more creative?" or "where are the Chinese Nobel Prize winners?" In essence, the question being asked is "how can our educational system be adjusted or organized to increase production of socially or scientifically valuable innovative ideas and products?" Creativity, like leadership, thus becomes defined in terms of particular goals and results rather than as a natural human process that can often run counter to established norms or goals (Ivcevic and Mayer 2009; Lee and Seo 2006; Runco 2010).

Torrance (1974), for example, defines creativity in terms of process of growing sensitivity to "problems," "deficiencies," or "disharmonies" within established sets of knowledge. His characterization runs parallel to the initial stages of a scientific process, as described by Dewey (1933) and Kerlinger (1986); the emergence of a personal, emotional feeling that something isn't quite right. This understanding of creativity as an emergent educational process is expressed by Yong Zhao's (2007) assertion that schools can't "teach" creativity but can only "kill it less" by allowing ample space for it to grow. Carson (2011) describes this space as one marked by "cognitive disinhibition," a willingness to consider ideas that seem strange, irrelevant, or otherwise beyond the boundaries of existing rules or structures. Understanding creativity in terms of a process encouraged or reinforced by environmental conditions enables it to be viewed separately from its products, as a natural force of emergent innovation, moving in various directions, with or without preconceived assumptions about its eventual results.

Within organizations, one notes a parallel with respect to leadership. Acts of creativity and leadership-i.e., attempted innovation-challenge and seek to expand the organization's zone of acceptance. In this way, creativity and leadership pose a common problem for educational systems. They are perceived as desirable organizational traits and outcomes, but must often emerge from the deconstruction of familiar and formal routines and structures that work implicitly or explicitly block creative activity. One such structure, similar to one previously 
discussed with respect to leadership, involves norms regarding the determination and allocation of the "right" to exercise creativity. In East Asian contexts, these include a belief that individuals "earn" the right to exercise creativity after long periods of rigorous study and successful intellectual or artistic production (Ma 2014). For example, though Chinese pre- and primary school-aged children may be allowed to engage in creative activity, an absence of demonstrably high skill will gradually limit their opportunity, as they are gradually pressed toward learning knowledge needed for success on high school and college entrance exams. After demonstrating this success, they may once again earn the status necessary to engage in career-related creative work.

Though American students may enjoy more opportunities for creative expression-especially outside of the classroom-status bias may also work to discourage creative work within classrooms. That is, a "mantle of creativity" tends to be reserved for those perceived to have earned it through the previous production of valuable work (Boden 2004). E. E. Cummings and John Cage may have produced masterfully unusual works of literature and music. But young students attempting to write or perform in similar styles may face considerable resistance from teachers. Additionally, classroom creativity may be restricted in other ways. Kennedy (2005) notes, for example, how time and curricular constraints press teachers to ignore or discourage creative questions or topics originating from students. Though both kinds of restrictions seem understandable, they nevertheless reflect the problem implicit in Yong Zhao's earlier cited observation about the schooling's potential to kill or encourage creativity.

\section{Creativity and leadership: essential connections}

Simonton (1988) has argued that leadership and creativity are, if not essentially the same thing, close manifestations of one another. Both involve envisioning and constructing novel ideas, goods, or actions whose value is undetermined at the time of inception and whose acceptance depends on a suspension of collective judgment and gradual mobilization of collective volition. Both thus involve an effort to expand a zone of acceptance within potential markets and among potential followers. Both involve the changing of hearts and minds as communities gradually accept ideas, goods, or actions they had not previously considered relevant or valuable. Social and organizational settings can thus be viewed as contested space, or policy fields (Bourdieu 1992), for the various multi-directional efforts of individuals or groups to expand the zones of peers, subordinates, or superiors.

Yet, as discussed previously, though schools value the utilitarian results of creativity and leadership, their generative processes pose risks to organizational stability. And because educational systems place such high value on the successful products of creativity and leadership, they gradually redefine them in terms of valued results. This misunderstanding promotes system stability, gradually infuses the larger institutional environment (e.g., demands for higher test scores, political interests, colleges of education), and constrains emergent creative-leader forces that might otherwise flow throughout a policy field. The perception that such emergent forces are disruptive or messy is fueled by the fact that they may not always lead to successful results.

Creativity and leadership, as conceived here, thus require schools to accept some measure of "disorder" or "deviance" in the sense of allowing useful fractures to occur in existing educational thought, structure, and routine (Runco 2010). They press students, teachers, parents, administrators, and other actors within schooling's institutional environment to become comfortable with discomfort and to suspend judgment over ideas which at first seem at odds with accepted routines. As this occurs, leadership and creativity represent the social tools necessary for fracturing, reshaping, and ultimately renewing the value of everyday routines.

This process is suggested by the learning path of a musician moving from novice student to creative artist. In early stages of learning, structure predominates: the recitation of scales, exercises, and established musical scripts. Over years of work within this structure, the artist finds the need and ability to trouble, fracture, and expand it. The resulting combination of structure and deviance (Hope 2010) in turn challenges and troubles the audience. In 1965, for instance, at a major US folk music festival, Bob Dylan's musical shift from acoustic folk to electric rock initially receives a negative response. At the same festival 1 year later, folk-rock is the prevailing musical style and Dylan receives thunderous applause. Common in fields of music, art, and literature, the slow drift from "troubled" to "valued" occurs in organizational settings, but is impeded by entrenched institutional assumptions. For example, a smart phone may be an excellent learning device, but its use by students is often prohibited within schools for reasons of organizational stability. ${ }^{1}$ Though not every creative idea is successful, and many are messy, the creative challenge in life and in education is not about offering people things they already appreciate; rather, it is to persuade them — and lead them — to value things they previously did not.

\footnotetext{
${ }^{1}$ Many American school districts, e.g., New York City Public Schools, still ban the possession of cell phones or other similar devices by students.
} 


\section{Creativity and leadership as organizational vectors}

Creativity and leadership thus thrive on and seek to generate cognitive disinhibition within a social setting-to expand the social-psychological space in which individuals or groups store and preserve the ideas or imperatives they have accepted over time. In schools, this is often a contested field, as evidenced by various multi-directional efforts of individuals to expand the zone of acceptance among their organizational peers, subordinates, and superiors.

Thus, like winds of change, one may think of leadership and creativity as vectors across organizational space, varying in direction and magnitude over time. In terms of direction, while lower-positioned members of an organization may gradually accept the judgments of higherpositioned members, a principal may also gradually accept the ideas of a teacher or a teacher those of a student. Though sometimes conflictive, this type of "dynamic subordinancy" (Crockett 1981) has long been considered vital even for rigid hierarchical organizations (e.g., the military). The risks of its absence are illustrated by the classic novel and film The Caine Mutiny as well as by numerous stories from Chinese history and literature of literal and figurative efforts to "change the emperor's mind" (Andrew and Lefleur 2014).

Envisioning creativity and leadership as organizational vectors requires the clarification of some key variables related to direction and magnitude. For the moment, we may think of direction in terms of whether the influence is exerted upward, downward, or horizontally; however, as shall be discussed later, the force may move in more than one direction. For magnitude, we employ Hemphill's (1949) three levels of leader action—attempted, successful, and effective-a framework that can also be applied to creative acts. Attempted creative-leader activity occurs when efforts to innovate or persuade fail to move beyond a very small audience. Successful acts are those that mobilize some degree of collective volition, but fail to achieve desired goals. Effective acts are those that mobilize volition and achieve desired goals. Shouse and Lin (2010) illustrates these levels of action as horizontal sections of an equilateral triangle and notes that effective efforts make up the smallest, but most socially visible proportion of action. The largest proportion of creative-leader effort occurs and remains at the attempted level and thus tends to be less visible to social observers.

History and literature, of course, provide numerous examples of these levels of impact on scales large and small and in a wide assortment of social settings. The 1950s American film, High Noon, for instance, portrays the fear and anguish of a town marshal heroically struggling, but totally failing, to persuade fellow citizens to help him defend the town against four murderous outlaws who have vowed to kill him. The Chinese film Pretty Big Feet (美丽 的大脚) portrays the successful efforts of a teacher over many years to instill the importance of education throughout her rural agrarian village. And, of course, the persistent and ultimately effective efforts of Deng Xiao Ping are widely known today. Less well known, perhaps, are the continuing efforts of individuals, such as Chinese artist Ai Wei Wei, who persist in efforts to combine art and social critique. Indeed, the present essay represents an attempt to creatively lead whose success or effectiveness is far from being determined.

Such narratives and actions prompt consideration of an additional vector-type characteristic related to both leadership and creative effort, that is its capacity to change in magnitude over time. Some efforts begin with high visibility and impact, but gradually fade. Others begin in small, unobserved corners of an organization or community, but gradually grow more visible, successful, and effective. In fact, this characteristic of leader/creator effort reflects a key argument made throughout this essay that schools and other organizations can be thought of as vector fields of potential leadership and creative effort. These fields comprise various emergent multi-directional sources of innovative capacity that are often overlooked, discouraged, dismissed, or suppressed as the meanings of creativity and leadership become institutionalized and routinized. The following authentic narrative - a miniature case study analysis-illustrates how a vector model can help us understand the multi-directional flow of leadership within organizations.

\section{A Taiwan math teacher's dilemma}

In 2002, a junior high school math teacher working on his $\mathrm{PhD}$ at a university in southern Taiwan raised the following question to his American professor. "Our education officials are asking schools to implement reform. They want us to change the way we teach and the way students learn. They want us to use less lecture and more active learning assignments. Do you have any ideas for us?"

The professor thought for a moment and replied, "Could you take your students outside of the classroom to do some math projects? For example, measure the height of flagpole using shadows and angles?"

The student paused for a moment, then replied, "It would not be allowed."

"Why?" asked the professor.

Another pause. "It would not be safe," replied the student. A bit surprised, the professor reminded the student that his school had a wall around it, a guarded gate, and that 
students gathered, socialized, and played together on campus every day without adult supervision. After another moment passed, the student replied, "It simply wouldn't be allowed."

The professor spent days and weeks thinking about the meaning and implications of the student's reply. First, he understood the normative barrier implicit in the student's words. In Chinese thinking, school is a place where teachers stand at the front of designated rooms at designated times while students sit in neat rows to listen, write, or recite. Though there might be times for students to be outside of their classroom, math period was not one of them. The institutional legitimacy of any activity-even educational activity - that altered this routine would be of great concern to all relevant observers. Second, the professor was struck nevertheless by the apparent potential confluence of four streams: creativity, leadership, order, and disorder. In other words, could a teacher imagine an innovative idea, persuade others of its value, and ultimately fracture and reconfigure the existing order? The professor understood that this process would be most difficult within a hierarchical organizational environment with rigid linkages between rank and authority. Still, he wondered, would it be possible for the teacher to mobilize volitional force around a creative idea-to lead?

\section{Analysis}

Though he may not have realized it, our Taiwan math teacher was confronted with the challenge and, perhaps, the responsibility of creative-leader action. We assume that to accept this challenge would require persistence and courage over time as well as the capacity to exercise dynamic subordinancy, that is to try to expand the principal's zone of acceptance through dialog or other trust-building interactions. "I have an idea. Can I show you? Can we try in once? Can we try it after school? Next semester?" The principal may at first reject the idea of outdoor math projects, but over time may be moved by the teacher's professional confidence, expertise, and apparent dedication to the overall good of the school. In cautious fashion, depending upon cultural norms, the teacher may attract colleague interest in the idea, which may in turn also influence the principal.

If the teacher can successfully change the principal's mind, a larger parallel task remains that of changing minds throughout the school. Returning to the vector analogy, one may conceive of the school as representing a three-dimensional vector space in which an innovative force has emerged. Figure 1 attempts to capture this force vector along dimensions of time, hierarchical change (influence with principal), and horizontal change (influence with colleagues). The two dark curved arrows represent the

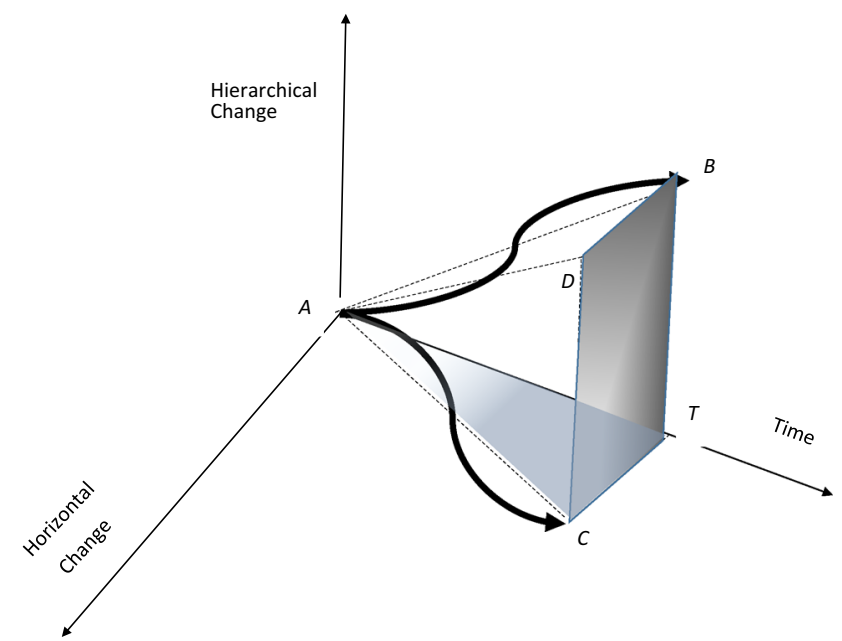

Fig. 1 Creativity and leadership as multi-directional organizational force

nonlinear path of persuasion over time associated with the teacher's innovation. In this case, the rectangle TBDC indicates that by time $T$ then has been influenced more than has the teaching staff in general. AB could be thought of as the teacher's vector of creative leadership with respect to the principal. AC represents that same force with respect to colleagues. It is important to note, however, that the influence represented by these vectors becomes gradually cumulative, diffuse, communal, and no longer applied solely by the teacher. In other words, the large pyramidshaped vector, ABCDT, can be thought of as comprising various subcurrents of persuasion, influence, or resistance over time.

Figure 1 also invites us to imagine creative-leading activity beyond terms of being a quality of individuals or of communities. In fact, we may think of creative-leader action as a nested force working from individuals, to larger groups, and to larger organizational or social units. The success of outdoor learning in one school may lead to its expansion into other schools. Over time, the potential exists for outdoor learning to problematize popular notions as to the very meaning of "school." The struggle to create and to lead thus shifts to a larger policy field in which there will be resistance from other actors. In East Asia as well as in the USA, for instance, movements toward alternative forms of schooling face stark opposition from assorted institutional interests such as government, teacher unions, and even colleges of education (Illich 1971; Shouse 2013).

Keeping in mind this idea of a nested force over a policy field, we invite readers to imagine the creative-leader vectors representing other examples and levels of school innovation. For example, a newly appointed principal of a poorly performing Taipei high school engaged her community in a process of cognitive disinhibition by 
suggesting the creation of a school orchestra. Though many teachers and parents saw little relevance in this idea (instead favoring tighter discipline and higher standards), the principal reported an overall improvement in student engagement and academic performance. ${ }^{2}$ To the extent her report was valid, we may expect to see other schools move in similar directions. Potential resistance within a policy field, however, is reflected in the words of a Korean educational researcher who upon viewing a news report about an American middle school's elaborate Broadway musical production remarked that although the students', teachers', and parents' energy and talent were impressive, she would question the academic quality of Korean schools conducting that sort of activity. ${ }^{3}$ Thus, while Fig. 1 suggests a vector meeting resistance along two dimensions, the two examples cited here suggest how the dimensions of any creative-leader process will increase as it moves from individual to organizational unit to larger policy field.

\section{Implications and conclusions}

The arguments and examples presented in this essay highlight the tight connection between educational leadership and creativity. In schools, classrooms, communities, and larger social contexts, each can fuel the other. Yet, the examples also underscore their sharp conflict with many of the deep normative structures of educational systems. For East Asian schools, the conflict grows as globally influenced expectations regarding the need for educational creativity clash with existing structures and local expectations regarding the importance of traditional testing. Evaluated primarily on test scores, teachers, schools, parents (and perhaps many students) may view creative instructional activity as a risky distraction (Burton 2010; Cheng 2010; Cropley 2010; Halstead and Zhu 2009).

It seems reasonable to imagine, however, that by gently and usefully fracturing such structural constraints, dissatisfied administrators, teachers, parents, and students can lead their schools beyond them. Imagine what might have resulted, for instance, if our Taiwanese math teacher had actually persisted in efforts to lead his principal and school to accept the idea of learning outside the classroom. Even if initially limited in scope or frequency, the activity could have had gradually growing effects throughout or even beyond the school.

Based on our experience, we believe that many administrators and teachers in East Asian schools want to innovate and that many students and parents would appreciate their creative-leader efforts. Allowing this to

\footnotetext{
${ }^{2}$ Based on interviews with Taiwan teachers, March 2009.

${ }^{3}$ Authors' personal experience and notes.
}

happen, however, will require educators to trouble and encourage their colleagues and students to accept and coexist with the often discomforting tensions associated with creative-leading. This troubling process need not be highly conflictual and can occur in small, incremental fashion as interested educators call their colleagues' attention to areas where rigid structures might be gently fractured-the "sweet spots" for school creativity and leadership that can be found in both curricular and metacurricular areas of school life. In terms of curriculum, such effort might include the modest fracturing of school time so as to allow regular opportunities for teachers and students to explore knowledge, ideas, and approaches outside the boundaries of formal testing or evaluation. At a metacurricular level, the effort involves permitting a flow of intellectual freedom, the expression of interest and talent outside the formal curriculum, and an allowance for individuals' sense of professional, academic, and artistic efficacy. Such efforts do not require extreme or sudden change. A door opened even slightly can permit the flow of refreshing breezes and interesting melodies.

Yet key questions remain. Does East Asia really want creative-leader efforts in its schools? If so, why? Are the ideas and actions of creativity and leadership, as presented in this article, really critical to the future technical success of East Asian education? Should reform initiatives be read more in symbolic than technical terms? That is, are they fueled, as Meyer and Rowan (1977) might describe it, more by global mythologies and concerns over institutional legitimacy than by actual deficiencies of academic quality? Finally, we would ask, can East Asian educational systems produce Noble Prize winners simply by expanding and improving the efficiency of their current routines?

At this point, we can only suggest that symbolism and rhetoric may be nearly as important as the actual implementation of new technical routines. In other words, discussions and policies concerning the need for leadership, creativity, or reform may be aimed more at spirit, motivation, or morale within educational systems than at actual instructional practice. We find indirect evidence of this in cases where traditional classroom activities become redefined as "creative." Some East Asian educators, for example, claim to "creatively" engage students via the study and memorization of "great works" of literature or history, while others point to computer-based classroom learning as a form of "educational creativity" (Dello-Iacovo 2009; Kipnis 2011). Perhaps, at this stage, what matters more is not the actual technical change, but the language surrounding the change. In East Asia and USA alike, the words with which we surround the acts of teaching, creating, and leading can promote the innovative confidence and energy needed to offset the powerful currents of test-driven education. East Asian educational 
reform is thus likely to expand as teachers become recognized and described in ways that promote their status and rights to attempt creative-leader activity outside their classrooms and throughout their schools.

We would also suggest or, rather, loosely speculate (as we have only impressionistic anecdotal data) that school reform reflects a deeper desire for greater social freedom, especially in China, a nation where such desire would likely be expressed mostly in indirect fashion. Suzhi Jiaoyu may, in fact, be seen as a means to indirectly trouble some of the country's long-standing social or institutional assumptions.

As touched on earlier, this essay itself represents an attempt to trouble, fracture, and reconfigure the language and meanings that have come to surround institutional understandings of creativity and leadership. Our arguments aim at East Asia as well as the USA where trends toward centrally standardized goals and routines meet increasing resistance from teachers, parents, and others willing to exercise an opposing creative-leader force. It is our hope that this essay will help researchers and policy makers identify and examine the cultural and institutional barriers that impede the free flow of creative-leader action.

\section{References}

Andrew, A., \& LeFleur, R. (2014). Remonstrance: The moral imperative of the Chinese scholar-official. Education about Asia, 19(2), 5-8.

Barnard, C. (1938). The functions of the executive. Cambridge: Harvard University.

Begley, P. (2002). Western-centric perspectives on values and leadership: Cultural isomorphs of educational administration. In A. Walker \& C. Dimmock (Eds.), School leadership and administration: Adopting a cultural perspective (pp. 45-60). New York: Routledge Falmer.

Boden, M. A. (2004). The creative mind: Myths and mechanisms. London: Routledge.

Bourdieu, P. (1992). An invitation to reflexive sociology. Chicago: University of Chicago.

Burton, P. (2010). Creativity in Hong Kong schools. World Englishes, 29, 493-507.

Carson, S. (2011). The unleashed mind: Why creative people are eccentric. Scientific American, 22(2), 22-29.

Cheng, V. M. Y. (2010). Tensions and dilemmas of teachers in creativity reform in a Chinese contest. Thinking skills and creativity, 5, 120-137.

Crockett, W. (1981). Dynamic subordinancy. Training and Development Journal, 35(5), 155-164.

Cropley, A. (2010). Creativity in the classroom: The dark side. In D. Cropley, et al. (Eds.), The dark side of creativity. New York: Cambridge.

Csíkszentmihályi, M. (1996). Creativity: Flow and the psychology of discovery and invention. New York: Harper Collins.

Dello-Iacovo, B. (2009). Curriculum reform and 'quality education' in China: An overview. International Journal of Educational Development, 29, 241-249.
Dewey, J. (1933). How we think. Boston: Heath.

English, F. (2006). The unintended consequences of a standardized knowledge base in advancing educational leadership preparation. Educational Administration Quarterly, 42, 461-472.

Haller, E., \& Strike, K. (1986). An introduction to educational administration: Social, legal, and ethical perspectives. New York: Longman.

Halstead, M. J., \& Zhu, C. (2009). Autonomy as an element in Chinese educational reform: A case study of English lessons in a senior high school in Beijing. Asia Pacific Journal of Education, 29(4), 443-456.

Hemphill, J. K. (1949). Situational factors in leadership. Columbus: Ohio State.

Hope, S. (2010). Creativity, content, and policy. Arts Education Policy Review, 111, 39-47.

Hoy, W., \& Miskel, C. (1996). Educational administration: Theory, research, and practice. New York: McGraw Hill.

Illich, I. (1971). Deschooling society. New York: Harper \& Row.

Illich, I. (1973). Tools for conviviality. New York: Harper \& Row.

Ivcevic, Z., \& Mayer, J. D. (2009). Mapping dimensions of creativity in life space. Creativity Research Journal, 21, 152-165.

Kennedy, M. (2005). Inside teaching: How classroom life undermines reform. Cambridge: Harvard University.

Kerlinger, F. N. (1986). Foundations of behavioral research. Fort Worth, Tex.: Holt, Rinehart and Winston.

Kipnis, A. B. (2011). Governing educational desire: Culture, politics, and schooling in China. Chicago: The University of Chicago.

Kozbelt, A., Beghetto, R. A., \& Runco, M. A. (2010). Theories of creativity. In J. C. Kaufman \& R. J. Sternberg (Eds.), The Cambridge handbook of creativity. Cambridge: Cambridge University Press.

Lee, E. A., \& Seo, H.-A. (2006). Understanding of creativity by Korean elementary teachers in gifted education. Creativity Research Journal, 18, 237-242.

Leithwood, K. A., \& Riehl, C. (2005). What do we already know about educational leadership? In W. A. Firestone \& C. Riehl (Eds.), A new agenda for research in educational leadership (pp. 12-27). New York: Teachers College.

Lockette, K. F. (2012). Creativity and Chinese education reform. International Journal of Global Education, 1, 34-39.

Ma, C. (2014). Informal socio-educational leadership and its expression through Chinese cinema. (Doctoral dissertation). Retrieved from ProQuest Dissertations and Theses. (****).

Meyer, J. W., \& Rowan, B. (1977). Institutionalized organizations: Formal structure as myth and ceremony. American Journal of Sociology, 83, 340-363.

Runco, M. A. (2010). Creativity has no dark side. In D. Cropley, et al. (Eds.), The dark side of creativity. New York: Cambridge.

Sargent, T. (2011). New Curriculum reform implementation and the transformation of educational beliefs, practices, and structures: A case study of Gansu province. Chinese Education and Society, 44, 49-74.

Selznick, P. (1957). Leadership in administration: A sociological interpretation. New York: Harper \& Row.

Shouse, R. (2012). Creativity, leadership, and a challenge for East Asian education. Korean Journal of Educational Administration, $30(2), 253-264$.

Shouse, R. (2013). Deschooling twenty-first century education. International Journal of Illich Studies, 3(2), 6-16.

Shouse, R. C., \& Lin, K. (2010). Principal leadership in Taiwan schools. New York: Rowman and Littlefield.

Simonton, D. K. (1988). Creativity, leadership, and chance. In R. J. Sternberg (Ed.), The nature of creativity: Contemporary psychological perspectives. Cambridge: Cambridge University.

Spillane, J. P. (2006). Distributed leadership. San Francisco: JosseyBass. 
Torrance, E. P. (1974). Torrance Tests of Creative Thinking. Scholastic Testing Service, Inc.

Weick, K. E., \& Westley, F. (1996). Organizational learning: Affirming an oxymoron. In S. R. Clegg, C. Hardy, \& W.
R. Nord (Eds.), Handbook of organizational studies (pp. 441458). London: Sage.

Zhao, Y. (2007). Education in the flat world. Implications of globalization on education. Edge, 2(4), 3-19. 